\title{
Collagen synthesis in fibroblasts from human colon: regulatory aspects and differences with skin fibroblasts
}

\author{
M F W C Martens, C M L C Huyben, Th Hendriks
}

\begin{abstract}
The purpose of this study was to examine regulation of collagen synthesis in human colon fibroblasts and compare the results from colon fibroblasts with those obtained in fibroblasts from human skin. The effects of interleukin-1 $\beta$, tumour necrosis factor $\alpha$, interferon gamma, transforming growth factor- $\beta$, dexamethasone, and the calcium ionophore A23187 were investigated. All compounds were tested both in the absence and in the presence of fetal calf serum in the culture medium. The process of collagen synthesis in fibroblasts from colon and skin appears to be affected differently by these regulatory compounds. The most pronounced differences were that the relative collagen synthesis increased in dermal fibroblasts and decreased in colon fibroblasts upon addition of serum. In the presence of serum, interleukin- $1 \beta$ inhibited collagen synthesis in skin fibroblasts but not in colon fibroblasts. Dexamethasone suppressed the relative collagen synthesis in skin fibroblasts but not in colon fibroblasts. Transforming growth factor- $\beta$ stimulated the collagen synthesis in dermal fibroblasts in the presence of serum, but inhibited the process in colon fibroblasts. Because fibroblasts are the primary sources of collagen needed during wound repair, these results may offer (part of) the explanation why wounds in skin and intestine appear to behave differently under certain conditions.
\end{abstract}

(Gut 1992; 33: 1664-1670)

Surgery, University

Hospital Nijmegen,

Nijmegen, The

Netherlands

M F W C Martens

C L M C Huyben

Th Hendriks

Correspondence to:

Dr Th Hendriks, Dept

General Surgery, University

Hospital Nijmegen, PO Box

9101, $6500 \mathrm{HB}$ Nijmegen,

The Netherlands.

Accepted for publication

31 May 1992

Wound healing is defined as a highly regulated sequence of various cellular events leading to reconstitution of tissue integrity after injury. ${ }^{\prime}$ Fibroblasts play an important role in this sequence by producing extracellular matrix components such as the different types of collagen and fibronectin..$^{2-4}$ Collagen is particularly important for the development of wound strength. In skin wounds, the increase in hydroxyproline parallels the increase in tensile strength. ${ }^{5}$ Also, a direct relationship is observed between collagen diameter and tensile strength. ${ }^{6}$ Collagen metabolism is closely controlled during the process of wound repair. Regulation is probably achieved by the interaction of fibroblasts with the surrounding extracellular matrix as well as by cytokines and growth factors known to regulate specifically collagen gene expression and collagen metabolism..$^{7-9}$

Most studies on wound healing have used skin, mainly because of the easy accessibility of this tissue. Although one would certainly like to think that all wounds heal by a single common mechanism, various authors ${ }^{10-12}$ have expressed caution in extrapolating the results from research on skin repair to the healing of other soft tissues such as intestine. Anastomotic repair in the intestine has been a topic of study in our laboratory for some time. ${ }^{13} \mathrm{We}$ have indeed found indications that intestinal wounds and skin wounds react differently to in vivo administration of various drugs. For instance, administration of methylprednisolone does not affect strength or collagen content of intestinal anastomoses while impairing healing in skin. ${ }^{1+}$ Also, administration of D-penicillamine, a lathyrogen which inhibits collagen cross linking, leaves anastomotic strength and collagen solubility unaffected while it lowers strength and increases collagen solubility in skin wounds. ${ }^{15}$ Although various explanations for these phenomena are possible, the question arises if production and metabolism of collagen in wounds of intestine and skin are under different control.

TABLE I Effect of serum on collagen and non-collagenous protein synthesis

\begin{tabular}{|c|c|c|c|c|}
\hline & \multicolumn{2}{|l|}{$H S F$} & \multicolumn{2}{|l|}{$H C F$} \\
\hline & $10 \%$ serum & $0 \%$ serum & $10 \%$ serum & $0 \%$ serum \\
\hline $\begin{array}{l}\text { Dpm } \\
\text { Collagenase } \\
\text { digestible } \\
\text { protein/well }\end{array}$ & 27299 (7299) & 7194 (2979) & $56730(5904)$ & $20842(589)$ \\
\hline $\begin{array}{l}\text { Dpm } \\
\text { Non-collagenous } \\
\text { protein/well }\end{array}$ & $164301(34204)$ & $114442(52967)$ & $464064(40956)$ & $117774(33346)$ \\
\hline$\%$ RCS & $3.09(0.49)$ & $1.30(0.69)$ & $2 \cdot 22(0 \cdot 06)$ & $3.27(0.44)$ \\
\hline
\end{tabular}

Synthesis was measured in both cell lines cultured in the presence and absence of fetal calf serum. Results represent average values (SD) from five separate experiments.

$\mathrm{HSF}=$ human skin fibroblasts; $\mathrm{HCF}=$ human colon fibroblasts.

\section{Methods}

MATERIALS

All supplies for cell culture were purchased from Life Technologies (Breda, The Netherlands). Transforming growth factor- $\beta$ from bovine bone 
was a gift from Dr G Ksander (Celtrix Labs, Palo Alto, USA). Interferon gamma was obtained from Boehringer (Ingelheim, Germany). Both

TABLE II Effect of IL-1 $\beta$ on collagen and non-collagenous protein synthesis

\begin{tabular}{|c|c|c|c|c|c|}
\hline & \multirow[b]{2}{*}{$I L-1 \beta U / m l$} & \multicolumn{2}{|l|}{$H S F$} & \multicolumn{2}{|l|}{$H C F$} \\
\hline & & $10 \%$ serum & $0 \%$ serum & $10 \%$ serum & $0 \%$ serum \\
\hline $\begin{array}{l}\text { Collagenase } \\
\text { digestible } \\
\text { protein/well } \\
\text { Non- } \\
\text { collagenous } \\
\text { protein/well } \\
\% \text { RCS }\end{array}$ & $\begin{array}{r}0 \\
1 \\
50 \\
0 \\
1 \\
50 \\
0 \\
1 \\
50\end{array}$ & $\begin{array}{c}100(14) \\
77(14) \\
69(2)^{\star} \\
100(13) \\
98(12) \\
98(11) \\
100(11) \\
78(4)^{\star} \\
67(4)^{\star}\end{array}$ & $\begin{array}{c}100(6) \\
64(10)^{\star} \\
50(9)^{\star} \\
100(6) \\
98(11) \\
83(11) \\
100(3) \\
67(4)^{\star} \\
62(4)^{\star}\end{array}$ & $\begin{array}{l}100(10) \\
108(19) \\
104(8) \\
100(9) \\
106(12) \\
126(6)^{\star} \\
100(3) \\
102(8) \\
83(3)^{\star}\end{array}$ & $\begin{array}{c}100(6) \\
103(14) \\
49(5)^{\star} \\
100(12) \\
112(5) \\
90(10) \\
100(5) \\
92(12) \\
56(12)^{\star}\end{array}$ \\
\hline
\end{tabular}

Both colon fibroblasts (HCF) and skin fibroblasts (HSF) were grown in $10 \%$ serum or serum free culture medium with different concentrations of interleukin-1 $\beta$. Results are expressed as percentile values with regard to the control cultures without interleukin-1 $\beta$. Data represent average values (SD) of four cultures. Differences between control and cytokine treated cultures are tested for significance using a two sided Wilcoxon's test: ${ }^{\star} \mathrm{p} \leq 0 \cdot 05$.

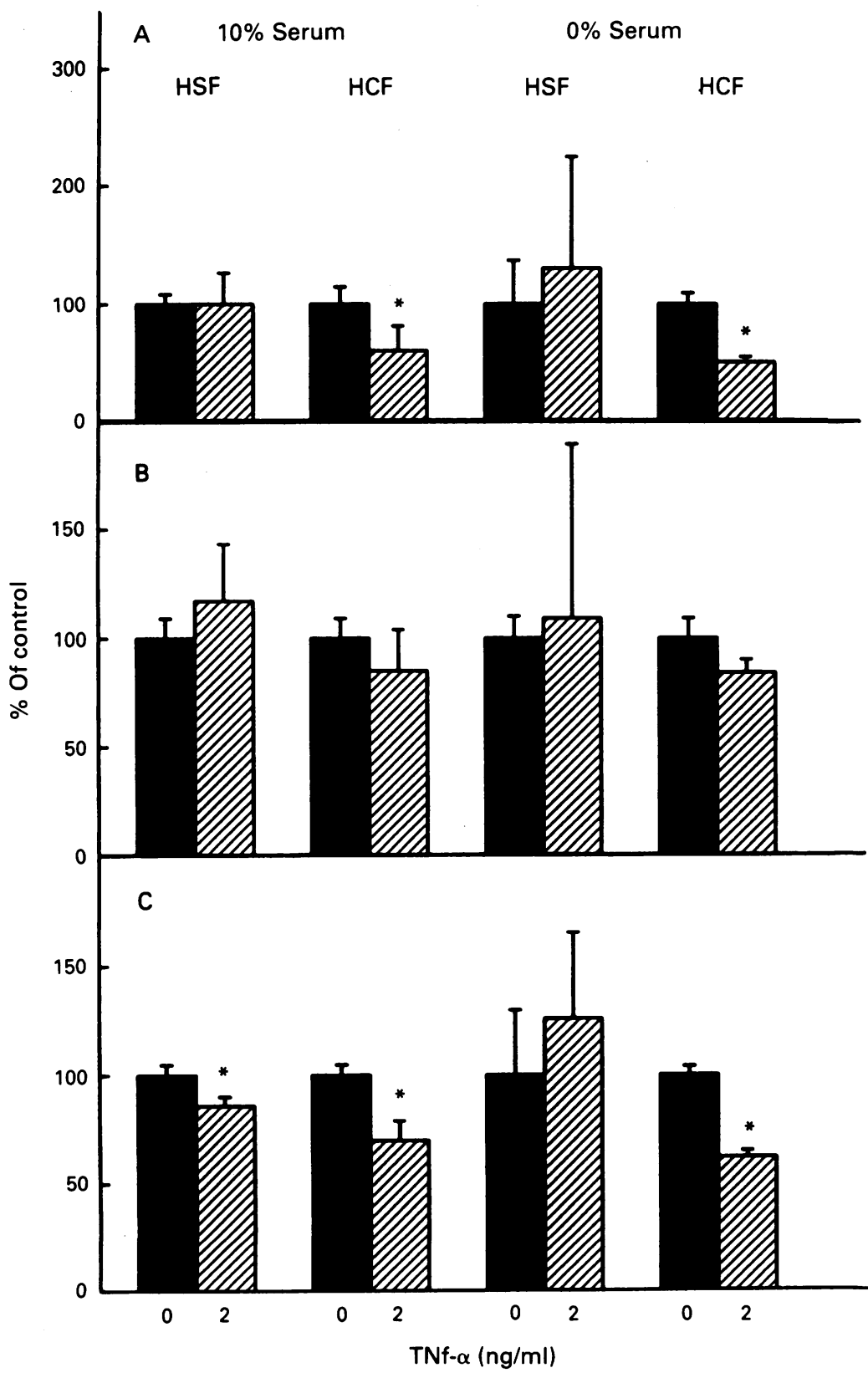

Figure 1: Effect of tumour necrosis factor- $\alpha(T N F-\alpha)$ on collagen and non-collagen protein synthesis. Visually confluent fibroblasts from both cell lines were incubated for 48 hours with or without tumour necrosis factor- $\alpha$, both in the presence or absence of fetal calf serum. Results are expressed as percentage of control without added tumour necrosis factor- $\alpha$. Values represent absolute collagen synthesis $(A)$, synthesis of non-collagenous protein $(B)$ or the relative collagen synthesis $(C)$. The average value $(S D)$ of four cultures is given. Differences between control and cytokine treated cell cultures are tested for significance using a two sided between control and cytokine treated cell cultures are teste human recombinant interleukin- $1 \beta$ and tumour necrosis factor $\alpha$ were a gift of Professor Dr J W $M$ van der Meer (University Hospital Nijmegen). $\mathrm{L}-\left[2,3-{ }^{3} \mathrm{H}\right]$ proline $(1,63 \mathrm{Tbq} / \mathrm{mmol})$ was purchased from Amersham International, England. Collagenase (type VII), calcium ionophore (A23187) and dexamethasone were obtained from Sigma (St Louis, USA). All other reagents were of analytical grade (Merck, Darmstadt, Germany)

\section{CELL CULTURE}

Normal human colon fibroblasts were obtained from the American Type Culture Collection (CRL-1459). Human skin fibroblasts were obtained from explants of skin biopsies of a healthy adult. Both the human skin fibroblasts and human colon fibroblasts were grown in Dulbecco's Modified Eagles Medium supplemented with antibiotics $(100 \mathrm{lU} / \mathrm{ml}$ penicillin and $100 \mu \mathrm{g} / \mathrm{ml}$ streptomycin) and $10 \%$ fetal calf serum at $37^{\circ} \mathrm{C}$ in a $5 \% \mathrm{CO}_{2}, 95 \%$ air humidified atmosphere. Cells were used between the third and tenth passage.

ASSAY OF FIBROBLASTS COLLAGEN PRODUCTION Collagen production by steady state, visually confluent fibroblasts was assessed over a 24 hour period by $\left[{ }^{3} \mathrm{H}\right]$ proline incorporation into collagenous protein.

Freshly trypsinised fibroblasts were plated in six well plates at a density of approximately $1.5 \times 10^{5}$ cells/well in $2 \mathrm{ml}$ Dulbecco's Modified Eagles Medium plus $10 \%$ fetal calf serum. Three days after plating the medium was removed and replaced by the same medium or with Dulbecco's Modified Eagles Medium without serum. In the latter case the wells were first washed twice with phosphate buffered saline. Twenty four hours later the medium was replaced by the same medium plus ascorbic acid $(50 \mu \mathrm{g} / \mathrm{ml})$, $\beta$-aminopropionitrile $(50 \mu \mathrm{g} / \mathrm{ml})$ and $2 \mu \mathrm{Ci} / \mathrm{ml}$ $\left[2,3-{ }^{3} \mathrm{H}\right]$ proline for the final 24 hours of culture. Interleukin- $1 \beta$, tumour necrosis factor $\alpha$, interferon gamma, transforming growth factor- $\beta$, dexamethasone or calcium-ionophore A23187 were added during the labelling period. Interleukin- $1 \beta$ and tumour necrosis factor $\alpha$ were also added during the 24 hour culture period before the labelling period. If the calcium ionophore was given, $1.5 \mathrm{mM} \mathrm{CaCl}_{2}$ was simultaneously added to the culture medium.

After the labelling period the cells and medium were scraped from the wells and the wells were washed twice with $1 \mathrm{ml} 50 \mathrm{mM}$ Tris- $\mathrm{HCl} \mathrm{pH} \mathrm{7.6}$ containing $25 \mathrm{mM}$ ethylenediaminetetraacetic acid, $10 \mathrm{mM}$-ethylmaleimide, $1 \mathrm{mM}$ phenylmethylsulphonylfluoride and $1 \mathrm{mM}$ proline. The wash solution was added to the suspension which contained cells and medium. The final suspension was freeze/thawed three times and the proteins were precipitated with trichloroacetic acid (final concentration $10 \%$ ). The radioactive protein was separated from free $\left[{ }^{3} \mathrm{H}\right]$ proline by repeated $(3 \times)$ washes with $5 \%$ trichoroacetic acid containing $1 \mathrm{mM}$ proline at $4^{\circ} \mathrm{C}$.

The final sediment was dissolved in $0.75 \mathrm{ml}$ $0.2 \mathrm{M} \mathrm{NaOH}$ and neutralised by the addition of 
$0.3 \mathrm{ml} 1 \mathrm{M}$ HEPES and $0.3 \mathrm{ml} 0.15 \mathrm{M} \mathrm{HCl}$. Aliquots from this solution $(0 \cdot 1 \mathrm{ml})$ were counted to determine the incorporation in total protein. In order to determine proline incorporation into collagen $0.2 \mathrm{ml} 20 \mathrm{mM}$ Tris- $\mathrm{HCl}, \mathrm{pH} 7 \cdot 6$, containing $50 \mathrm{mM} \mathrm{CaCl}_{2}$ and $0 \cdot 1 \mathrm{ml}$ collagenase (chromatographically purified on a G200 gel filtration column) were added to a $0.5 \mathrm{ml}$ aliquot of the solubilised sample and the mixture was incubated for five hours at $37^{\circ} \mathrm{C}$. The digestion was terminated by the addition of trichoroacetic acid and tannic acid up to final concentrations of $0.6 \mathrm{M}$ and $3 \mathrm{mM}$, respectively. After centrifugation (10 minutes, $14.500 \mathrm{~g}$ ) a $1.0 \mathrm{ml}$ aliquot of the supernatant was counted in a liquid scintillation analyser. The same procedure was followed without the addition of collagenase. Subtraction of the counts released in this blank incubation from those released in the presence of collagenase

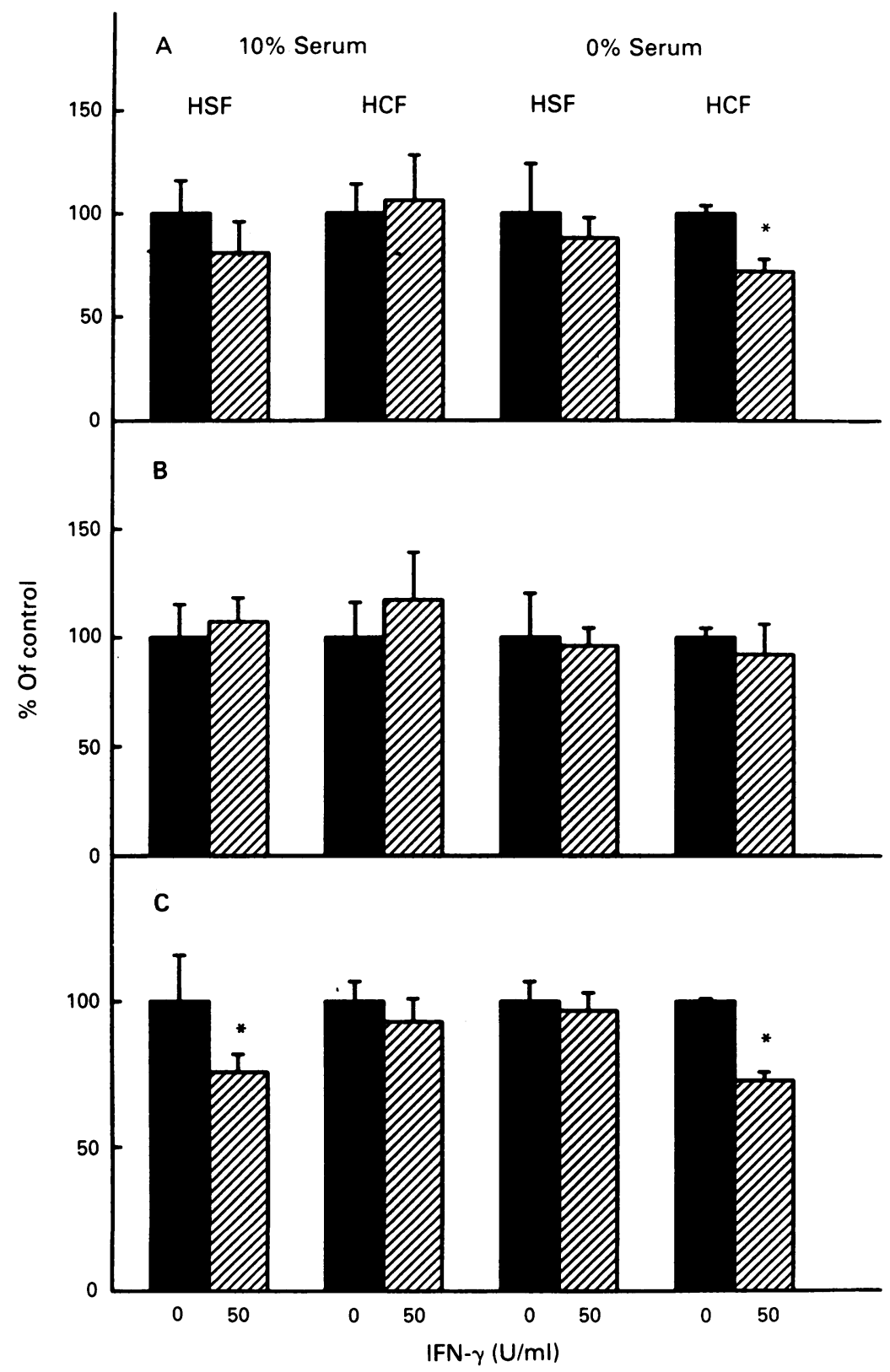

Figure 2: Effect of interferon gamma on collagen and non-collagen protein synthesis. Visually confluent fibroblasts from both cell lines were incubated for 24 hours with or without interferon gamma, both in the presence or absence of fetal calf serum. Results are expressed as percentage of control without added interferon gamma. Values represent absolute collagen synthesis $(A)$, synthesis of non-collagenous protein $(B)$ or the relative collagen synthesis $(C)$. The average value $(S D)$ of four cultures is given. Differences between control and cytokine treated cell cultures are tested for significance using a two sided Wilcoxon's test: ${ }^{\star} p \leq 0.05$. yielded the collagen specific incorporation, which will be referred to as collagenase digestible protein. Subtraction of the radioactivity in the collagenase digestible protein fraction from that in total protein yields the incorporation into noncollagenous protein. Incorporation into collagenase digestible protein and non-collagenous protein is quantified per well.

The relative collagen synthesis was calculated with the formula ${ }^{17}$ that takes into account the enrichment of proline in collagen compared with other proteins:

$\%$ relative collagen synthesis $=$ collagenase digestible protein

$\overline{(\text { non-collagenous protein } \times 5 \cdot 4)+\text { collagenase digestible protein }} \times 100 \%$

\section{Results}

Collagen synthesis in the two fibroblast strains was always measured the presence and in the absence of $10 \%$ serum. In the presence of serum, human colon fibroblasts produce more collagen and non-collagenous protein than human skin fibroblasts (Table I). This difference is maintained if the incorporation of label into the fractions is expressed per cell (results not shown). If serum is omitted, synthetic capacity decreases. The absolute collagen synthesis is lowered by 63 and $74 \%$ in human colon fibroblasts and human skin fibroblasts, respectively. The synthesis of non-collagenous protein, however, is affected far more strongly in human colon fibroblasts. As a result, serum free conditions cause the relative collagen synthesis to be more than halved in human skin fibroblasts and to be increased by nearly $50 \%$ in human colon fibroblasts.

Cytokines are potential regulators of protein synthesis. In human colon fibroblasts cultured with serum the absolute collagen synthesis is not affected by interleukin-1 $\beta$ (Table II). As the synthesis of non-collagenous protein increases with the higher concentration of interleukin- $1 \beta$ used, the relative collagen synthesis is lowered. In the absence of serum, both absolute and relative collagen synthesis are inhibited by $50 \mathrm{U} /$ $\mathrm{ml}$ interleukin-1 $\beta$. The collagen synthesis in skin fibroblasts appears far more susceptible to the cytokine; the lower concentration suppresses synthesis independent of the presence of serum. The bulk of non-collagenous protein synthesis remains unaffected by the addition of interleukin-1 $\beta$.

Tumour necrosis factor $\alpha$, at a concentration of $2 \mathrm{ng} / \mathrm{ml}$, does not affect the synthesis of noncollagenous protein in either of the fibroblast strains (Fig 1). If the skin fibroblasts are cultured without serum, no effect on collagen synthesis is observed. In the presence of serum, the relative collagen synthesis is reduced by $14 \%$. The potentially inhibitory effect of tumour necrosis factor $\alpha$ is more explicit in the human colon fibroblasts under both culture conditions. For instance, the absolute collagen synthesis is reduced by $50 \%$ if cells are grown without added serum. At lower concentrations, 0.02 and $0.2 \mathrm{ng} / \mathrm{ml}$, tumour necrosis factor $\alpha$ induces no alterations in synthetic activity (results not shown).

Both cell lines react essentially similar to the addition of interferon gamma to the culture 
medium. Again, total protein synthesis remains unaffected, while collagen synthesis is lowered (Fig 2). In human skin fibroblasts however the decrease is more apparent in the presence of serum while in human colon fibroblasts significantly reduced collagenase digestible protein and $\%$ relative collagen synthesis values are only observed after culture without serum.

The synthetic activity in human colon fibroblasts is hardly affected by the glucocorticoid dexamethasone (Fig 3): in the presence of serum neither the collagen synthesis nor the synthesis of non-collagenous protein changes after addition of the drug. Both activities appear to be stimulated in serum free cultures, at least at the higher concentrations of dexamethasone. As a result, the relative collagen synthesis remains

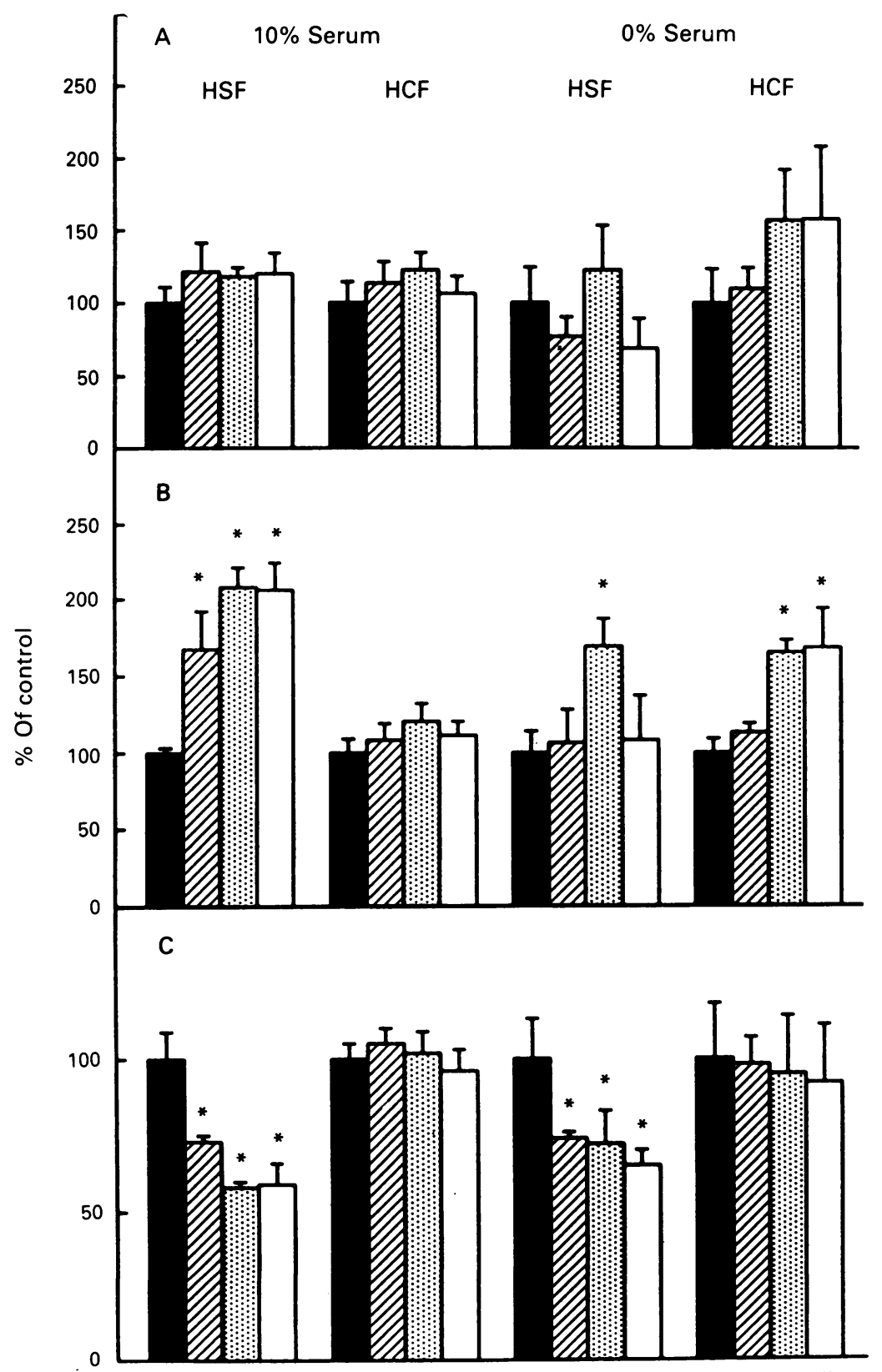

Figure 3: Effect of dexamethasone on collagen and non-collagen protein synthesis. Visually confluent fibroblasts from both cell lines were incubated for 24 hours with or without dexamethasone, both in the presence or absence of fetal calf serum. Results are expressed as percentage of control without added dexamethasone: black bars represent controls, striped bars $10^{-9} \mathrm{M}$, dotted bars $10^{-7} \mathrm{M}$ and open bars $10^{-5} \mathrm{M}$ dexamethasone. Values represent absolute collagen synthesis $(A)$, synthesis of non-collagenous protein $(B)$ or the relative collagen synthesis $(C)$. The average value $(S D)$ of four cultures is given. Differences between control and dexamethasone treated cell cultures are tested for significance using a two sided Wilcoxon's test: ${ }^{\star} p \leq 0 \cdot 05$. unaffected. Human skin fibroblasts react differently; in the presence of serum the synthesis of non-collagenous protein is doubled by dexamethasone while the absolute collagen synthesis is not influenced. Thus, the relative collagen synthesis decreases significantly, from concentrations of $10^{-9} \mathrm{M}$ dexamethasone upwards.

Another way to regulate collagen synthesis in colon fibroblasts is the addition of the calcium ionophore A23187. While no effects are observed in the presence of serum (results not shown), culturing cells in the presence of $0.6 \mu \mathrm{M} \mathrm{A23187}$ suppresses the collagen synthesis by more than $75 \%$ (Fig 4). Although human skin fibroblasts are also found to be susceptible to the presence of the ionophore the picture seems somewhat different: the significant decrease in the relative collagen synthesis appears more a result from an increase in synthesis of non-collagenous protein than from a lowered absolute collagen synthesis.

Growth factors, and especially transforming growth factor- $\beta$, are thought to stimulate fibroblast collagen synthesis. This is indeed the case in human skin fibroblasts, regardless of culture conditions (Fig 5). In both cases, the absolute and relative collagen synthesis are increased, although the latter less so in $10 \%$ serum since here the synthesis of non-collagenous protein is also significantly enhanced. Human colon fibroblasts react just the opposite, at least in the presence of serum. Both collagen and noncollagenous protein synthesis are suppressed significantly. In the absence of serum, collagen synthesis in human colon fibroblasts is enhanced by transforming growth factor- $\beta$, particularly at a concentration of $5 \mathrm{ng} / \mathrm{ml}$. The synthesis of other proteins, however, is stimulated to the same extent and thus the relative collagen synthesis remains unchanged.

Finally, we investigated if transforming growth factor $\beta$ could negate the inhibitory effects of interferon gamma and A23187 on collagen synthesis in colon fibroblasts cultured under serum free conditions. As shown before, both interferon gamma and A23187 significantly suppress collagen synthesis, absolute and relative, while transforming growth factor- $\beta$ stimulates absolute collagen synthesis. Transforming growth factor $-\beta$ is able to overcome the negative effects of interferon gamma (Table III): if added simultaneously, values for the parameters observed are similar to those observed in the presence of transforming growth factor- $\beta$ alone. In contrast, transforming growth factor $-\beta$ cannot restore the inhibition induced by A23187. Culture in the presence of both compounds results in a massive suppression of collagen synthesis, similar to that induced by $A 23187$ alone.

\section{Discussion}

Collagen synthesis is an essential and universal feature of wound repair. After construction of an anastomosis in the intestine the synthetic capacity is strongly, and specifically raised in the wound area. ${ }^{1819}$ Because collagen synthesis is thought to be crucial to the development of anastomotic strength, the study of its regulation is of great potential interest. Leakage of colonic 
anastomoses is a phenomenon that occurs quite frequently ${ }^{20}$ and insight into regulation of the processes which are essential in the repair sequence could contribute to the development of measures to avoid this complication. The cells most likely to be responsible for collagen synthesis are the fibroblasts which migrate into the wound and display great proliferative activity. Thus, we investigated collagen synthesis in an established line from human colon fibroblasts ${ }^{21}$ and compared the results with those obtained with fibroblasts from human skin. In the literature on fibroblast collagen synthesis discrepancies between studies are often explained by supposedly different culture conditions, particularly with respect to the presence of serum. ${ }^{22}$ In order to discover if such variations in culture conditions indeed change the effects of the

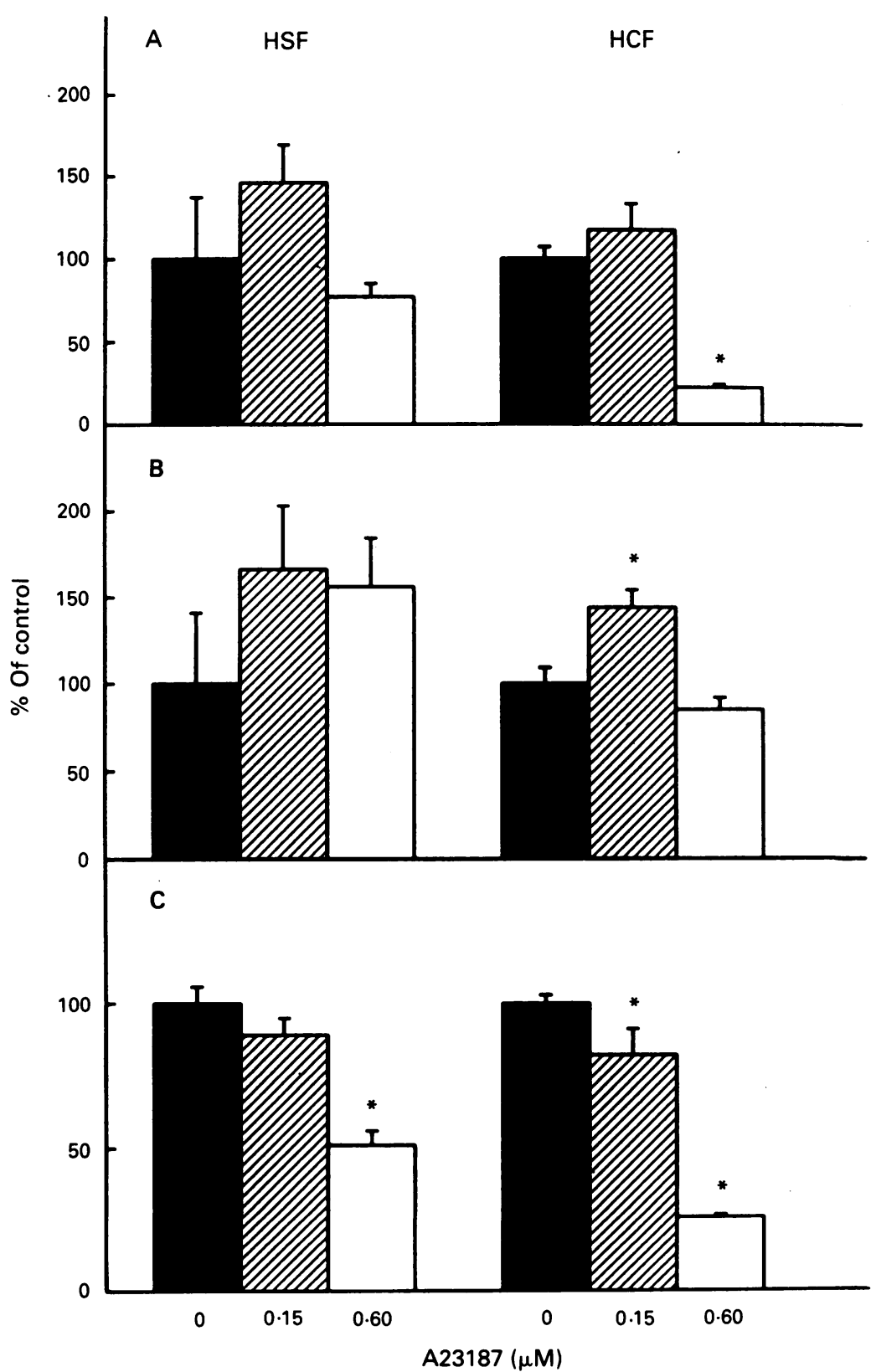

Figure 4: Effect of calcium ionophore A23187 on collagen and non-collagen protein synthesis. Visually confluent fibroblasts from both cell lines were incubated for 24 hours with or without A23187, in absence of fetal calf serum. Results are expressed as percentage of control without added A23187. Values represent absolute collagen synthesis $(A)$, synthesis of non-collagenous protein $(B)$ or the relative collagen synthesis $(C)$. The average value $(S D)$ of four cultures is given. Differences between control and ionophore treated cell cultures are tested for significance using a two sided Wilcoxon's test: ${ }^{\star} p \leq 0.05$. regulatory compounds studied, synthetic activity was measured both in the presence and absence of serum.

It has been shown that addition of serum to fibroblast cultures stimulates collagen synthesis, ${ }^{23}$ probably at the transcriptional level..$^{24}$ Although colon fibroblasts behave similarly in this respect they seem to be unique in the sense that the synthesis of non-collagenous protein is stimulated to a greater degree, resulting in a lower relative collagen synthesis under serumsupplemented conditions.

Interleukin-1B inhibits collagen synthesis in colon fibroblasts cultured in the absence of serum. We found similar results for skin fibroblasts, which observation is in agreement with those reported by others. ${ }^{22}{ }^{25}$ The fact that such inhibition was not seen in the presence of serum confirms a similar observation by Duncan and Berman, ${ }^{26}$ although our skin fibroblasts are also responsive under these conditions and display a suppressed collagen synthesis.

Tumour necrosis factor $\alpha$ inhibits the collagen synthesis in colon fibroblasts. A similar effect with comparable tumour necrosis factor concentrations has been reported for skin fibroblasts, ${ }^{27} 28$ while our own results show that only the relative collagen synthesis decreases in skin fibroblasts cultured in the presence of serum. These data contradict those of others ${ }^{26}$ who show an increased collagen synthesis in dermal fibroblasts cultured without serum.

Studies on interferon gamma show that this compound universally inhibits collagen synthesis in a variety of target cells - for example, fibroblasts ${ }^{2729}$ and fetal bone cultures. ${ }^{30}$ In this respect, colon fibroblasts are no exception although significant inhibition is only measured under serum free conditions.

Neither the absolute nor the relative collagen synthesis in colon fibroblasts are significantly affected by dexamethasone. Most studies with skin fibroblasts indicate that glucocorticoids reduce collagen synthesis ${ }^{31}$ : decreased concentrations of mRNA suggest pretranslational regulation..$^{32}$ In the present study, a reduction in the absolute collagen synthesis is only apparent, and not significantly so, if dermal fibroblasts are grown without serum. The decreased relative collagen synthesis is, certainly in serum supplemented cultures, the result of a stimulation in the synthesis of non-collagenous protein. In animal studies we have found that colonic wound healing is unaffected by administration of corticosteroids at doses which impair dermal wound healing. ${ }^{14}$ Therefore, it is interesting to observe that collagen synthesis in fibroblasts from colon seems refractory to corticosteroids. Possibly, a difference in regulation of this fibroblast function may (partly) explain the divergent healing patterns in both tissues.

Growth factors, and especially transforming growth factor- $B$, are known to stimulate collagen synthesis in fibroblasts from a variety of tissues. ${ }^{33-35}$ Our results with dermal fibroblasts confirm earlier results reported for cells from this tissue. In contrast, synthetic activity in human colon fibroblasts is significantly inhibited in the presence of serum. While there has been a report on negative effects of transforming growth 


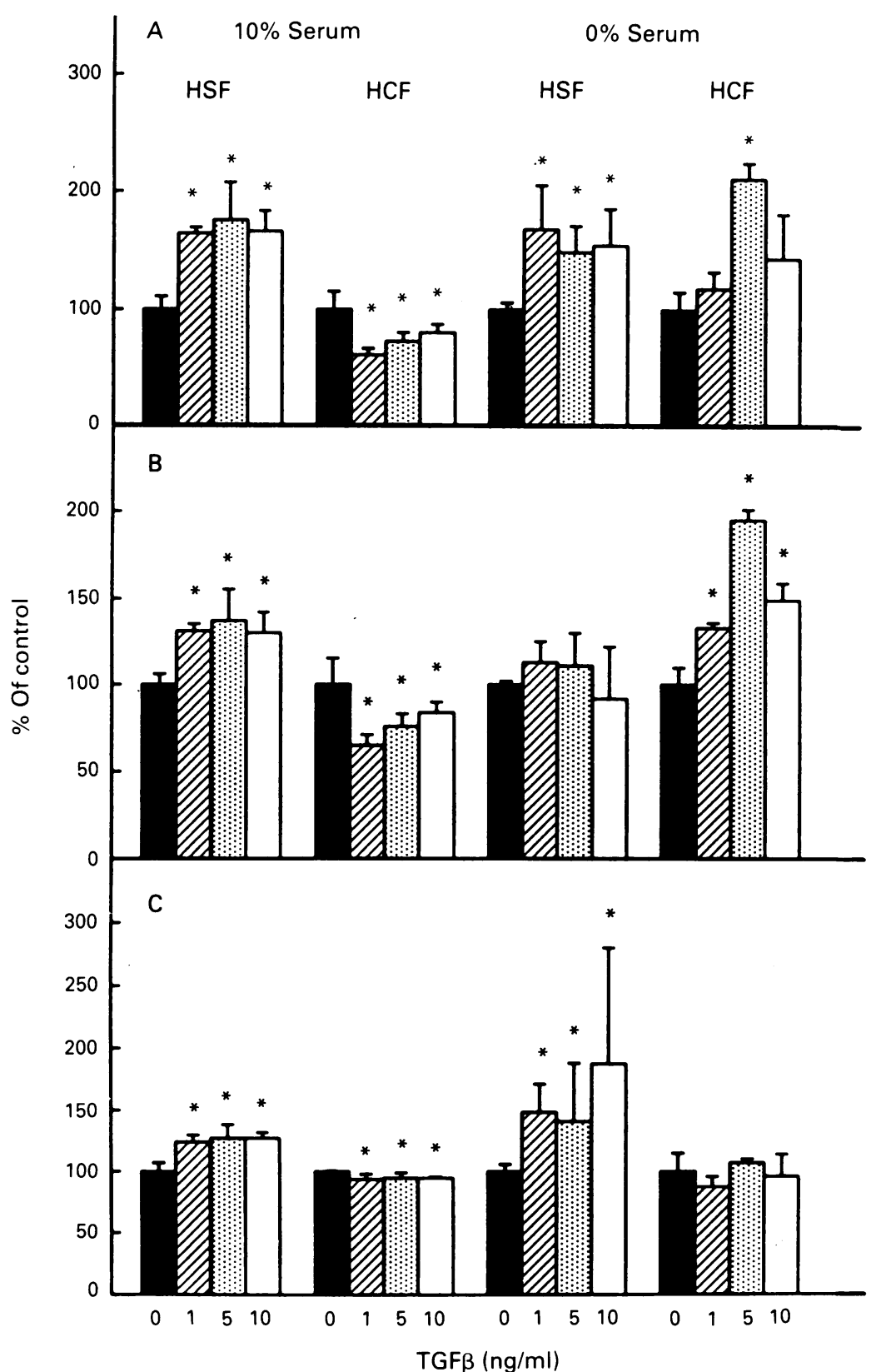

Figure 5: Effect of transforming growth factor- $\beta$ on collagen and non-collagen protein synthesis. Visually confluent fibroblasts from both cell lines were incubated for 24 hours with or without transforming growth factor- $\beta$, both in the presence or absence of fetal calf serum. Results are expressed as percentage of control without added transforming growth factor- $\beta$. Values represent absolute collagen synthesis $(A)$, synthesis of non-collagenous protein $(B)$ or the relative collagen synthesis $(C)$. The average value $(S D)$ of four cultures is given.

Differences between control and growth factor treated cell cultures are tested for significance using a two sided Wilcoxon's test: ${ }^{\star} p \leq 0.05$.

factor- $B$ on collagen synthesis in hepatocytes, ${ }^{36}$ this is the first evidence that transforming growth factor- $\beta$ may inhibit collagen synthesis in fibroblasts. Fukamizu and Grinell ${ }^{37}$ described decreased collagen synthesis in long term fibroblast cultures, possibly as the result of lowered

TABLE III Collagen synthesis in human colon fibroblasts under serum free conditions

\begin{tabular}{lccl}
\hline & CDP/well & NCP/well & $\%$ \%CS \\
\hline Control & $100(13)$ & $100(13)$ & $100(11)$ \\
+ Transforming growth factor- $\beta(10 \mathrm{ng} / \mathrm{ml})$ & $140(10)^{\star}$ & $146(4)^{\star}$ & $95(5)$ \\
+ Interferon gamma $(1000 \mathrm{u} / \mathrm{ml})$ & $61(5)^{\star}$ & $82(6)$ & $76(9)^{\star}$ \\
+Interferon gamma + transforming growth & $152(8)^{\star}$ & $153(9)^{\star}$ & $99(5)$ \\
factor- $\beta$ & $14(2)^{\star}$ & $71(7)^{\star}$ & $20(1)^{\star}$ \\
+A23187 $(0.6 \mu \mathrm{M})$ & $16(2)^{\star}$ & $79(3)^{\star}$ & $21(2)^{\star}$ \\
\hline +A23187+transforminggrowthfactor- $\beta$ & &
\end{tabular}

Cells were grown in serum free medium. Results are expressed as percentile values with regard to control cultures. Data represent average values (SD) of four cultures. Differences between control and other cultures were tested for significance using a two sided Wilcoxon's test: ${ }^{\star} p \leq 0 \cdot 05$. fibroblast activity concomitant with spatial reorganisation of the extracellular matrix. In the absence of serum, absolute collagen synthesis in colon fibroblasts is indeed stimulated by transforming growth factor- $B$ in a concentration of 5 $\mathrm{ng} / \mathrm{ml}$. At this concentration, transforming growth factor- $\beta$ can overcome the inhibition induced by interferon gamma under these conditions, suggesting that both cytokines affect collagen synthesis through the same regulatory pathway. Simultaneous exposure of either skin fibroblasts ${ }^{38}$ or gingival fibroblasts ${ }^{39}$ to both interferon gamma and transforming growth factor- $\beta$ did reverse the stimulation in collagen production observed with transforming growth factor- $\beta$ alone, suggesting the presence of independent mechanisms.

Increasing the intracellular calcium concentration by addition of the ionophore A23187 together with extra calcium to the culture medium strongly suppresses collagen synthesis in colon fibroblasts. If the ionophore is added together with transforming growth factor- $\beta$, collagen synthesis remains inhibited to the same extent. Thus it seems that the regulatory action of transforming growth factor- $B$ is dependent upon a low intracellular calcium level.

Next to investigating the behaviour of collagen synthesis in colon fibroblasts under addition of various regulatory compounds, the aim of this study was to establish if fibroblasts from colon and skin behave differently in this respect. This indeed appears to be the case. The relative collagen synthesis increases in dermal fibroblasts and decreases in colon fibroblasts upon the addition of serum. In the presence of serum interleukin- $1 \beta$ inhibits collagen synthesis in skin fibroblasts but not in colon fibroblasts. Dexamethasone suppresses the relative collagen synthesis in skin fibroblasts but not in colon fibroblasts. Transforming growth factor- $\beta$ stimulates the collagen synthesis in dermal fibroblasts cultured in the presence of serum but inhibits the process in colon fibroblasts.

The other differences observed are less explicit and merely a matter of degree and fall within the variations observed by us (results not shown) and others $^{26}$ for different cell lines from the same tissue. Those mentioned above, however, and most particularly the discrepancy measured in the presence of transforming growth factor- $\beta$, suggest that repair activities of fibroblasts in colon and skin may be under different control. Wound fibroblasts obtained from implanted sponges differ from normal dermal fibroblasts with regard to their capacity to synthesise collagen and remodel collagen lattices. ${ }^{10}$ Thus, the wound environment may alter fibroblast phenotype. Our results indicate that fibroblasts from skin and colon may exhibit divergent reactions to cytokines or growth factors produced during the inflammatory part of the healing sequence and therefore may cause wounds in skin and intestine to behave differently under certain conditions.

1 Clark RAF. Cutaneous tissue repair. Basic biological consid erations. F Am Acad Dermatol 1985; 13: 701-25.

Moriyama K, Shimokawa H, Susami T, Sasaki S, Kuroda T. Effects of growth factors on mucosal scar fibroblasts in culture - A possible role of growth factors in scar formation. Matrix 1991; 11: 190-6. 
3 Laato M, Kahari VM,Niinikoski J, Vuorio E. Epidermal growth factor increases collagen production in granulation tissue by stimulation of fibroblast proliferation and not by istivation of procollagen

4 Babu M, Diegelmann R, Oliver N. Fibronectin is overproduced by keloid fibroblasts during abnormal wound produced by keloid fibroblasts during

5 Madden JW, Peacock EE. Studies on the biology of collagen during wound healing. Rate of collagen synthesis and deposition in cutaneous wounds of the rat. Surgery 1968; 64: 288-94.

6 Doillon CJ, Dunn MG, Bender E,Silver FH. Collagen fiber formation in repair tissue development of strength and toughness. Collagen Rel Res 1985; 5: 481-92.

7 Mauch C, Hatamochi A, Scharffetter K, Krieg Th. Regulation of collagen synthesis in fibroblasts within a threedimensional collon gel. Exp. Cell Res 1988; 178: 493-503.

8 Postlethwaite AE, Raghow R, Stricklin GP, Poppleton H, Seyer JM, Kang AH. Modulation of fibroblast functions by interleukin 1: increased steady-state accumulation of type I procollagen mRNAs and stimulation of other functions but procollagen mRNAs and stimulation of other functions but and beta. $F$ Cell Biol 1988; 106: 311-8.

9 Hata RI, Sunada H, Arai K, Sato T, Ninomiya Y, Nagai Y, Senoo H. Regulation of collagen metabolism and cell growth by epidermal growth factor and ascorbate in cultured huma skin fibroblasts. Eur F Biochem 1988; 173: 261-7.

10 Zederfeldt B. Factors influencing wound healing. In: Viidik A, Vuust J, eds. Biology of collagen. New York: Academic Press, 1980: 347-62.

11 Forrest $\mathrm{L}$. Current concepts in soft connective tissue wound healing. BrF Surg 1983; 70: $133-40$.

12 Smith R. Recovery and tissue repair. Br Med Bull 1985; 41 : 295-301.

13 Hendriks Th, Mastboom WJB. Healing of experimental intestinal anastomoses: parameters of repair. Dis Colon Rectum 1990; 30: 891-901

14 Mastboom WJB, Hendriks Th, de Man BM, de Boer HHM The influence of methylprednisolone on the healing of intestinal anastomoses in the rat. Brf Surg 1991; 78: 54-6.

15 van Doorn K, de Man B, Hendriks Th. The effects of lathyrogens on intestinal anastomoses in the rat. $\operatorname{Exp} M o$ Pathol 1990; 52: 37-45.

16 Braskén P, Renvall S, Sandberg M. Fibronectin and collagen gene expression in healing experimental colonic anastomoses. Br F Surg 1991; 78: 1048-52.

17 Peterkofsky B, Chojkier M, Bateman J. Determination of collagen synthesis in tissue and cell culture. systems. In: Furthmayer $\mathrm{H}$, ed. Immunochemistry of the extracellular matrix. Vol 2. Boca Raton: CRC Press, 1981: 19-47.

18 Jonsson $\mathrm{K}$, Jiborn $\mathrm{H}$, Zederfeldt B. Comparison of healing in the left colon and ileum. Changes in collagen content and the left colon and leum. Changes in collagen content and collagen synthesis in the intestinal wall after ileal and colonic

9 Martens MFWC, Hendriks Th. Postoperative changes in collagen synthesis in intestinal anastomoses of the rat Differences between small and large bowel. Gut 1991; 32 : 1482-7.

20 Fielding FP, Stewart-Brown S, Blesovsky L, Kearney G. Anastomotic integrity after operations for large bowe cancer: a multicentre study. $B M 7$ 1980; $281: 411-4$.

21 Agrez MV, Chua FK. The role of colon fibroblasts in malignant large bowel obstruction - an experimental in vitro model. Br f Cancer 1990; 62: 567-72.

22 Mauviel A, Heino J, Kahari VM, Hartmann DJ, Loyau G Pujol JP, et al. Comparative effects of interleukin-1 and tumor necrosis factor- $\alpha$ on collagen production and correstumor necrosis factor- $\alpha$ on collagen production and corresponding procollagen messenger-RNA levels in h

23 Booth BA, Polak KL, Uitto J. Collagen biosynthesis by human skin fibroblasts. I. Optimization of the culture conditions for synthesis of type I and type III procollagens. Biochim Biophys Acta 1980; 607: 145-60.

24 Narayanan AS, Page RC. Serum regulation of collagen biosynthesis in human diploid fibroblasts. Biochem Biophys Res Commun 1987; 145: 639-45.

25 Bhatnager R, Penfornis H, Mauviel A, Loyau G, Saklatvala J, Pujol JP. Interleukin-1 inhibits the synthesis of collagen by fibroblasts. Biochem Int 1986; 13: 709-20.

26 Duncan MR, Berman B, Differential regulation of collagen, glycosaminoglycan, fibronectin and collagenase activity production in cultured human adult dermal fibroblasts by interleukin 1-alpha and beta and tumor necrosis factor-alpha and beta. $\mathcal{F}$ Invest Dermatol 1989; 92: 699-706.

27 Scharffetter K, Heckmann M, Hatamochi A, Mauch C, Stein $B$, Riethmuller G, et al. Synergistic effect of tumor necrosis factor-alpha and interferon-gamma on collagen synthesis of human skin fibroblasts in vitro. Exp Cell Res 1989; 181:409 19.

28 Mauviel A, Daireaux M, Redini F, Galera P, Loyau G, Pujol JP. Tumor necrosis factor inhibits collagen and fibronectin JP. Tumor necrosis factor inhibits collagen and fibronectin 236: 47-52.

29 Jimenez A, Freundlich B, Rosenbloom J. Selective inhibition of human diploid fibroblast collagen synthesis by interferons. F Clin Invest 1984; 74: 1112-6.

30 Smith DD, Gowen M, Mundy GR. Effects of interferongamma and other cytokines on collagen synthesis in fetal rat bone cultures. Endocrinology 1987; 120: 2494-9.

31 Oikarinen AI, Uitto J, Oikarinen J. Glucocorticoid action on connective tissue - from molecular mechanisms to clinical practice. Med Biol 1986; 64: 221-30.

32 Oikarinen A, Vuorio E, Vuorio T. Comparison of the effects of dexamethasone and 13-cis-retinoic acid on connective tissue biosynthesis in human skin fibroblasts. Arch Dermatol Res 1989; 281: 273-8.

33 Varga J, Rosenbloom J, Jimenez SA. Transforming growth factor beta (TGF-beta) causes persistent increase in steadystate amounts of type I and type III collagen and fibronectin mRNAs in human and dermal fibroblasts. Biochem $\mathcal{F} 1987$; 247: 597-604.

34 Eghbali M, Tomek R, Sukhatme VP, Woods C, Bhambi B. Differential effects of transforming growth factor-betal and phorbol myristate acetate on cardiac fibroblasts - regulation of fibrillar collagen messenger RNAs and expression of early transcription factors. Circulation Res 1991; 69: 483-90.

35 Raghu G, Masta S, Meyers D, Narayanan AS. Collagen synthesis by normal and fibrotic human lung fibroblasts and the effect of transforming growth factor-beta. Am Rev Respir Dis 1989; 140: 95-100.

36 Tsutsumi Y, Kakumu S, Yoshioka $K$, Arao $M$, Inoue $M$, Wakita $T$. Effects of various cytokines on collagen synthesis by normal rat hepatocytes in primary cultures and fibroblasts. Digestion 1989; 44: 191-9.

37 Fukamizu H, Grinnell F. Spatial organization of extracellular matrix and fibroblast activity - effects of serum, transforming growth factor beta, and fibronectin. Exp Cell Res 1990; 190: 276-82.

38 Varga J, Olsen A, Herhal J, Constantine G, Rosenbloom J, Jimenez SA. Interferon-gamma reverses the stimulation of collagen but not fibronectin gene expression by transforming growth factor-beta in normal human fibroblasts. Eur $7 \mathrm{Clin}$ Invest 1990; 20: 487-93.

39 Narayanan AS, Page RC, Swanson J. Collagen synthesis by human fibroblasts - regulation by transforming growth factor-beta in the presence of other inflammatory mediators. Biochem $\mathcal{F}$ 1989; 260: 463-9.

40 Regan MC, Kirk SJ, Wasserkrug HL, Barbul A. The wound environment as a regulator of fibroblast phenotype. $\mathcal{f}$ Surg Res 1991; 50: 442-8. 